\title{
MEMORIAL SOBRE A TRAJETÓRIA ESCOLAR BÁSICA DE DAYSE HELLEN COSTA DE VILHENA
}

\author{
Dayse Hellen Costa de Vilhena ${ }^{1}$
}

Resumo: O presente texto trata do memorial sobre a trajetória escolar de Dayse Hellen Costa de Vilhena, ex-integrante do Programa Conexões de Saberes. Tem como objetivo apresentar os passos percorridos desde o início da educação básica até a entrada à UFPA e quais os principais entraves de estudantes das comunidades populares adentrarem o ensino superior público. A memória foi usada como principal referência para construção do material. Em seus resultados, apresenta os esforços individual e coletivo para que de fato a educação seja uma questão de direito e não de privilégio de poucos.

O ingresso na Universidade Federal do Pará - UFPA move o sonho de muitos estudantes de todas as cores, classes e sexo, por ser um espaço de construção do conhecimento científico, leva muitos a acreditar no conhecimento como caminho para elevação da situação econômica e social. E na busca desse sonho é que agora escrevo sobre esse processo, que não pode ser analisado pela aparência, para não desconsiderar os fatores que contribuem para a concretização do sonho de entrar na Universidade pública. - tendo que passar pelo "rolo compressor" que seleciona os que "mais aptos" estiverem. Refletir sobre minha trajetória escolar, até chegar à universidade me faz lembrar de pessoas que encontrei, algumas fundamentais nesse caminho.

Falar desta trajetória sem deixar explícito o que considero minha base, meu alicerce, ficaria vazio. É caro leitor; estou falando de minha preciosa MÃE! Seu nome é Sandra. Devo a ela tudo na vida. O sonho e posteriormente a realidade de estar na Universidade é graças o incentivo dessa pessoa especial. Suas palavras sempre soaram em meus ouvidos..."A melhor herança que os pais podem deixar para os filhos é a educação". Com esperança em dias melhores, tal ideologia de vida que me impulsionou a lutar pelo desejo de entrar na universidade. Minha mãe aprendeu a ler e escrever sozinha, através de jornais e revistas. Ela começou a estudar há pouco tempo por exigência de seu recente emprego. Explico-lhes as razões. Minha avó materna vivia mudando de lugar com os filhos (sabe-se lá porque), não incentivava nem permitia que eles estudassem; após sua morte minha mãe, como primogênita, teve que assumir seus quatro irmãos; apesar disso, ela sempre acreditou que estudar seria o melhor caminho a seguir. Ainda que

\footnotetext{
${ }^{1}$ Graduação em Serviço Social pela Universidade Federal do Pará, e-mail: daysevilhena22@gmail.com
} 
naquele momento minha mãe desconhecesse e não ter tido acesso a escola enquanto instituição de ensino que garante educação enquanto direito do cidadão e dever do Estado, não mediu esforços para que seus irmãos tivessem a oportunidade que lhe foi negada. E mesmo com todo incentivo que deu para seus irmãos, nem todos concluíram o ensino fundamental, pois tiveram que trabalhar desde a infância como feirante (foi o que aprenderam e é o que fazem até hoje), talvez isso tenha desestimulado-os. Meus tios não conseguiram, porém minha mãe começou a fazer apostas nas filhas. Quem sabe, não passava pela sua cabeça que as mulheres não a decepcionariam? E com esse pensamento incentivou suas filhas, Shirley, Eu, Renata e Priscila, respectivamente.

Antes de falar da perspectiva de escolarização, situarei no tempo e espaço, como minha família se configurou. Como já disse somos 04 (quatro) irmãs (filhas da mesma mãe), poderíamos ser 05 (cinco), caso uma delas não tivesse falecido. Esse episódio modificou nossas vidas.

Quando Eliane ficou doente, ocasião em que veio falecer, minha avó (mãe do meu pai), levou-me para morar em sua casa e meu avô resolveu nos registrar eu, Eliane e Renata em seu nome. Em seu pensamento como suas filhas poderiam usufruir dos benefícios provenientes pelo fato dele ser servidor público da Universidade Federal do Pará - UFPA. Plano cheio de boas intenções. Parece engraçado, porém minha trajetória está ligada a esse espaço...Será destino?Não! Para chegar aqui na condição de aluna venci desafios. Naquele tempo apenas os filhos de funcionários da UFPA podiam estudar na Escola de Aplicação da UFPA (então Núcleo Pedagógico Integrado - NPI). Nessa escola passei grande parte de minha vida, da formação préescolar até o Ensino Médio. A escola era bem distante do bairro em que morávamos - Bengui por um tempo meu avô custeou o transporte escolar, pois a condição financeira era razoável.

As lembranças da escola são de uma criança desprovida de recursos. No período préescolar, lembro da professora Socorrinho. Quantas vezes ela mandou bilhetinho para casa por causa do meu sapato "com boca-de-jacaré”! Meu rendimento escolar também não era dos melhores. Às vezes não conseguia fazer o dever até a hora da saída e por isso ficava retida; em uma ocasião o Daniel ficou lá me esperando terminar, quando chegamos no estacionamento o ônibus não estava mais, comecei a chorar; então fomos até a portaria e um homem se aproximou de nós e perguntou o que havia acontecido, por coincidência ele era amigo de meu avô e nos levou para casa. Lembro também de uma faxineira da escola (infelizmente não lembro seu 
nome), quantas vezes eu deixei de entrar na fila da merenda escolar por vergonha e ela fazia isso por mim, afinal, a maioria dos "coleguinhas trazia seus lanchinhos". NPI, de "todos", do filho do reitor ao porteiro, assim as desigualdades sociais se apresentavam no âmbito escolar. Naquele momento como criança não tinha a capacidade de discernimento; só vergonha! Na Alfabetização a professora que chamávamos de tia Iara, tinha uma sensibilidade muito forte, na maioria das vezes percebia minhas limitações.

Em outras séries do ensino fundamental também encontrei certa ajuda para melhorar o rendimento escolar, posso citar aqui a Profa. Rosa de matemática, que me dava aula extraclasse; a Profa. Izabel Cristina, que convidava os alunos que tinham certa dificuldade de concentração, para umas aulas num programa de computador (programa da tartaruguinha); outra vez a direção da escola selecionou uns alunos para fazer um horário de estudo e também tinha outros objetivos que não lembro muito bem. Só sei que quando tinha algum programa para os alunos mais "burrinhos" eu estava lá. Brincadeiras a parte, esses pequenos projetos foram essenciais para a melhora do meu aprendizado.

É claro que a memória não nos permite lembrar cada momento, de cada pessoa ou de cada detalhe da nossa história de vida, mas alguns deixam marcas que o tempo não pode apagar, não é! Kelly foi uma dessas, uma amiga da infância que faz parte dessa história, estudamos até a $3^{\circ}$ série, quando eu repeti e ela passou para a $4^{\circ}$ série. Nela percebia uma boa personalidade, nos dávamos muito bem, apesar dos contrastes físicos e econômicos. Ela utilizava o mesmo ônibus escolar que eu, agradecia por ela descer primeiro, pois via sua bela casa e não queria que ela visse onde eu morava; parece bobagem mais naquele tempo aquilo fazia tanto sentido.

Em 1992, já na $2^{\circ}$ serie do ensino fundamental, minha avó adoeceu, voltei a morar com minha mãe, assim poderia fazer companhia para minha irmã Renata que começaria a estudar. Minha mãe sempre foi cozinheira, trabalhava vendendo comida ou em casa de família. Quando saía para trabalhar, já nos levava para esperarmos o ônibus escolar. Na volta, ficávamos esperando alguém ir nos buscar na parada de ônibus. Havia duas meninas, Núbia e Rosália que desciam do ônibus conosco, a casa delas era bem em frente à parada. Com o tempo fizemos amizade com elas e com seus pais, e muitas vezes passávamos o dia lá e só voltávamos para casa no final da tarde.

No ano de 1993, um acontecimento fez com que tivéssemos de deixar a casa onde morávamos. A mamãe teve que pedir refúgio na casa de minha avó paterna. Um dos irmãos de 
minha mãe se envolveu em uma briga de rua, atingindo com um cabo de aço o rosto de outro garoto; por isso nossa casa e de nossa família passou a ser ameaçada. Mas mudamos apenas de casa e não de Bairro. Na época, eram 07 pessoas para morar em um compartimento apenas, não era fácil. Passamos mais ou menos 01 (um) ano nesse cômodo na casa da vovó, até que finalmente mamãe conseguiu vender a casa e comprar outra, no mesmo bairro, onde moramos até hoje.

Em 1994, o papai também estava consolidando outra família, passando a morar próximo ao NPI, eu gostava muito de ir até lá, por causa de meus outros irmãos - Suziane, Junior e Danilo e também eles tinham um nível de vida um pouco melhor, que eu e minhas outras irmãs, assim eu podia também usufruir de alguns privilégios estando ao lado deles, mais sempre voltava para o lar de minha mãe.

O novo lar dava grande entusiasmo, pois a casa apesar de ser de velha e de madeira era grande, tinha três compartimentos! Aquilo parecia grande para quem só havia tido casa com um compartimento para muitas pessoas; a dimensão do terreno e as árvores frutíferas davam um gostinho de quero mais. Este lugar marca a história de vida de minha família. Essa casa apresenta-se como um marco, pois a partir dali as condições econômicas foram melhorando gradativamente. Os irmãos da mamãe já não dependiam tanto dela. Tivemos muitos desafios, mas minha mãe sempre acreditou que o futuro poderia ser melhor se estudássemos, e isso até hoje, se esforça muito para nos dar força, e continua a trabalhar até mesmo nos finais de semana. Queria ver minha mãe ficar irritada quando alguém pedia suas filhas ou para ser babá ou para morar em sua casa para ajudar nas tarefas domésticas. Não queria que nós fossemos morar com ninguém para trabalhar, como já disse, queria que nós estudássemos. Porém, minha irmã mais velha precisava trabalhar para ajudar no orçamento familiar, e por falta de opção foi em casa de família. Isso é quase rotina nas famílias de baixa renda.

$\mathrm{Na}$ escola, na sala de aula, em grupos ou em qualquer relação social, nos aproximamos mais de umas pessoas do que de outras, seja por identificação, afinidades ou interesses em comum. Nessa etapa destaco algumas pessoas que fazem parte da minha história. Mais ou menos entre a $5^{\circ}$ e a $8^{\circ}$ série do ensino fundamental meu grupo inseparável era a Alessandra Lima, Betânia e Hugo. Neles encontrei o que considero verdadeiros laços de amizade; mas momentos vão e vem. $\mathrm{Na} 8^{\circ}$ série conheci a Rafaela e ficamos amigas (até hoje mesmo não estando tão próximas, ainda "trocamos figurinhas") logo depois também nos aproximamos de Claúdia e da

Revista PET Interdisciplinar e Programa Conexões /UFPA On-line. Ed. Especial - 2017, BELÉM/ PA - ISSN 2447-097X 
Ananda que também eram muito apegadas. Esse foi o grupo que terminou comigo o ensino fundamental. Estava com 15 (quinze) anos, e nem tive festa. Quantos sonhos!

No Ensino médio, ano de 2001, outra fase em nossas vidas. No momento da matrícula os alunos tinham que optar por uma língua estrangeira; nem todos sabiam que as turmas agora seriam definidas de acordo com essa escolha. O primeiro dia de aula foi uma confusão, era mais quem queria voltar para sua turma anterior. Sei que o desafio de estar com outra turma estava lançado, mas comigo estavam Rafa, Claúdia e Ananda. Nesse ano conheci uma turminha do barulho que ainda aprontavam certas travessuras; as irmãs Larissa e Taissa, a Alessandra Tavares, e outras que não lembro tanto. Nessa fase a busca por novas aventuras era evidente, havia curiosidade em relação a temas comuns aos adolescentes como: Namoro, sexo, drogas, gravidez, enfim.

Mas, desde o início do Ensino Médio, já havia uma cobrança maior, em relação ao futuro, seja da família, dos professores ou da direção da escola. Agora, passava a ouvir com mais freqüência e rigor sobre processo seletivo e vestibular. Muitos alunos já se preparavam para o PRISE - Programa de Ingresso Seriado - e eu parecia que estava fora do contexto, afinal não tinha dinheiro para fazer a inscrição para a $1^{a}$ fase; portanto, não acompanhei este processo como alguns, mas naquele momento passar para o $2^{\circ}$ ano já era bom demais. $\mathrm{O}$ que não era bom era o fato de minha amiga Rafa ter sido reprovada, e teria que seguir sem ela; prometi esperá-la na série seguinte, mas motivos particulares não permitiriam. Ainda no Ensino Médio, visitei a secretaria algumas vezes, principalmente por atraso na hora da entrada ou falta do uniforme completo, já era adolescente e ainda tinha que passar por esses constrangimentos por falta de recursos financeiros.

No $2^{\circ}$ ano do ensino médio, me deparei com uma situação que parecia desesperadora, parecia o "fim do mundo", parece exagero mais foi o que senti. Eu estava grávida, com 16 anos de idade! Comecei o ano de 2001 sem saber o que fazer, contava com apoio do Neto, pai de minha filha, mas assim como eu ele também era muito novo e ainda nem trabalhava. $\mathrm{O}$ que mais me incomodava era a falta de coragem de contar para minha mãe, pois sabia que decepcionaria a pessoa mais importante da minha vida. Porém, ela não demorou a perceber. A notícia caiu como uma bomba na minha família, naquele dia minha mãe, eu e minhas irmãs choramos muito, como se fosse o fim de uma vida e não o começo de uma. Sempre ficaram ao meu lado. Por mim teria deixado de estudar, pois estava com vergonha de todo mundo da escola, da rua de casa, da minha 
família, queria me esconder; mas a mamãe não deixou que eu desistisse. Portanto, tomei a decisão de contar logo para todos da sala de aula, afinal estavam falando de greve; e geralmente a greve chegava a durar mais de três meses, pois a escola acompanhava as greves dos funcionários da Universidade Federal do Pará; assim queria evitar a cara de espanto das pessoas quando voltassem às aulas. Mas primeiro quis contar para a pessoa mais próxima de mim naquele momento da turma, que era a Claudia, e para minha surpresa quando fui contar, ela olhou para mim e disse: "junto comigo", a Claudia também estava grávida. Fiquei feliz, pois não teria que enfrentar sozinha aquela situação. Contei para todos da turma, que não acreditaram no primeiro momento. Infelizmente, a Claudinha desistiu de estudar naquele ano. Claro que fiquei triste. Ficava envergonhada, quase não saia da sala de aula para não ter que encarar mais pessoas, já bastava os da minha turma. Nesse ano recebi muita força da Alessandra Tavares, que hoje ainda é uma grande amiga, da Taissa e Larissa, na sala de aula, e da Rafa que mesmo não estudando comigo estava sempre pronta para me ajudar. Por ironia do destino depois de três meses Rafa me dá a noticia que também estava grávida, por opção! Talvez. Em casa procurava me esforçar o máximo nas tarefas para não aborrecer minha mãe, e sempre quando ela falava algo mesmo que ela não estivesse certa, não contestava, aceitava. Na sala de aula dormia muito e geralmente nas provas as meninas me davam uma "colinha". Mesmo não sendo "boa aluna" eu teria que passar, afinal era o que minha mãe esperava e naquele momento era o mínimo que poderia fazer para agradá-la. E quanto mais a barriga crescia, a preocupação aumentava em cuidar de uma criança também, afinal eu não queria nem estava preparada para ser mãe. Quando ela nasceu, o tempo, a força de minha mãe e irmãs e do pai dela a insegurança foi diminuindo e eu passei a amá-la cada dia mais e procurei vencer e buscar independência.

Enfim, apesar dos trancos e barrancos eu consegui ser aprovada para o $3^{\circ}$ ano de Ensino Médio. Agora tinha que conciliar a escola e um bebê; recebi apoio da minha família para essa maratona que seria o ano de 2002. Era o último ano para fechar mais uma fase da vida escolar. Era a primeira vez que iria prestar vestibular, apesar de estar entusiasmada, queria mesmo era conseguir concluir o Ensino Médio e conseguir um emprego. No final do ano impulsionada pelo espírito dos outros alunos não só da turma (muitos se dedicaram o ano todo) também me inscrevi para fazer a prova da UFPA e da UEPA. Em ambas consegui chegar até a última fase, mas não conseguir aprovação. Quando saiu o resultado, eu assisti como espectadora à festa das pessoas

Revista PET Interdisciplinar e Programa Conexões /UFPA On-line. Ed. Especial - 2017, BELÉM/ PA - ISSN 2447-097X 
aprovadas em 2003. Decidi que queria também participar da festa, na condição de protagonista. Comecei a alimentar o sonho de entrar na universidade.

No ano de 2003, tive minha $1^{\circ}$ experiência com cursinho preparatório para vestibular (era um cursinho popular ${ }^{2}$ ); e desse não guardo boas lembranças. Era a primeira vez que iria estudar a noite e o pior, estava acostumada com uma turma de no máximo 35 pessoas; quando me deparei com uma sala com mais ou menos 200 pessoas, foi assustador no momento, confesso, mas mesmo assim resolvi ficar. O problema era que o cursinho faliu e mudou de lugar por duas vezes atrapalhando o conteúdo, e para completar quando chegou próxima a última fase da prova eu não tinha mais como pagar a mensalidade do cursinho. Resultado, eu não fui aprovada (vestibular $2004-2^{\circ}$ que fiz) e no ano seguinte fiquei desestimulada em fazer cursinho.

Então, a partir do ano de 2004, tinha a intenção de conseguir um emprego para poder pagar um cursinho melhor. Mas, como milhões de jovens nessa fase da vida eu dei com a cara na porta em várias empresas, que queriam pessoas com experiência e capacitação e eu não tinha nem uma das duas coisas. Em 2005 fiz novamente o vestibular por tentativa, e apesar de não ter me preparado ficava esperando sair meu nome no listão, em vão! Era engraçado que sempre conseguia chegar até a última fase, e isso ao mesmo tempo me estimulava e desestimulava.

Nesse ano ainda não tinha conseguido um emprego, mas surgia uma luz, o "Programa de apoio ao $1^{\mathrm{o}}$ emprego, consórcio social da juventude wapokai" do governo federal; no qual os critérios para a seleção seriam jovens entre 16 e 24 anos em situação de vulnerabilidade social (baixa renda familiar, bairro periférico...). Fiz a inscrição e fui selecionada. Nesse período convivi com pessoas que tinham histórias bem parecidas com a minha e que alimentavam o sonho de obter um emprego e ajudar suas famílias. Fiz o curso de "Gestão em serviços de organização de eventos", recebíamos uma bolsa e éramos conscientizados do nosso papel na sociedade. A partir desse curso tive um contato maior com as entidades do Bairro, pois se exigia uma carga horária de voluntário (a). Foi aí que conheci o Núcleo de educação popular - NEP e percebi o engajamento dos membros com outros grupos e com os movimentos sociais. Fui levada ao "Fórum de Empreendedores solidários"; eu me sentia um "peixinho fora d'água"; pois não sabia muito bem o que estava fazendo ali. Ao termino do curso fui convidada para trabalhar numa

\footnotetext{
${ }^{2}$ Cursinho pré-vestibular, que cobra baixa taxa de mensalidade, que busca atender os estudantes de baixa-renda, que algumas vezes concedem bolsas para estudantes ou descontos uma vez que comprovem não ter condição de pagar.
}

Revista PET Interdisciplinar e Programa Conexões /UFPA On-line. Ed. Especial - 2017, BELÉM/ PA - ISSN 2447-097X 
cooperativa, cujo nome "Delícias do parámazônia"; estava em fase de estruturação; assim muitas mulheres desistiam do sonho que aquele empreendimento representava, pois queriam algo imediato. Passei mais ou menos um ano ali; como a renda era relativamente baixa e tinha a cobrança da família, deixei de freqüentar a cooperativa e passei a vender churrasco nos dias de semana num ponto que minha mãe alugou para vender comidas típicas, já que fora obrigada a deixar de trabalhar na casa de família em que trabalhou por mais de dez anos. Conheci pessoas que me fizeram querer buscar cada vez mais a esperança em dias melhores, como a Joana, a Frenny e a Frankelly. Mais o que realmente queria era passar no vestibular, mesmo não me dedicando totalmente como deveria, eu lia de vez em quando, ajudava minhas irmãs e quem me pedisse ajuda em matérias que aprendi. Quando chegou à época da inscrição da prova da Federal, mais uma vez não tinha dinheiro para pagar, mas fui incentivada por minha amiga, minha mãe vendo meu entusiasmo em fazer novamente a prova, conseguiu o dinheiro.

No dia do resultado, não tinha esperança que eu fosse passar, mais resolvi ouvir o resultado na rádio ${ }^{3}$ como de costume, e até porque meus dois irmãos que moravam com meu pai, também estavam na esperança de um bom resultado, já que haviam se preparado. Deixei de ajudar minha mãe para ouvir o listão dos aprovados. Antes de sair o curso de Serviço Social no qual me candidatei, meu primo Dayvison chegou e disse que eu havia passado, é claro não acreditei; até ouvir o meu nome completo pela rádio; foi uma sensação inexplicável não tem como descrever. Eu sei que aquela vitória não foi minha e sim de um conjunto de pessoas que contribuíram para que e fato fosse concretizado, e, principalmente a luta e força de vontade da minha MÃE.

O ano de 2006 foi surpreendente, pois ao mesmo tempo em que entrei na universidade minha mãe conseguiu um emprego numa creche, e poderia matricular minha filha (Alessandra) como bolsista, assim eu poderia estudar mais tranqüila. É! A história continua a trajetória de um Estudante Universitário de Origem Popular - EUOPs, não acaba com a entrada na Universidade, que é sem dúvidas um mundo novo, cheio de desafios. Agora a luta é juntar forças para que o espaço da universidade seja de fato democratizado. A trajetória pode ser entendida não apenas como individual, mas coletiva, como já foi dito por alguns.

\footnotetext{
${ }^{3}$ Até um tempo atrás era costume no Estado do Pará, as pessoas esperarem o listão dos aprovados da UFPA ser divulgado nas rádios e a marchinha do cantor da terra - Pinduca - Alô...Alô papai... ser a música inspiradora desse momento.
}

Revista PET Interdisciplinar e Programa Conexões /UFPA On-line. Ed. Especial - 2017, BELÉM/ PA - ISSN 2447-097X 